\title{
REVIEW
}

\section{Latest Approaches for the Treatment of Spasticity and Autonomic Dysreflexia in Chronic Spinal Cord Injury}

\author{
Alexander G. Rabchevsky ${ }^{1,2}$ and Patrick H. Kitzman ${ }^{1,3}$ \\ ${ }^{1}$ Spinal Cord \& Brain Injury Research Center, ${ }^{2}$ Department of Physiology, and ${ }^{3}$ Department \\ of Rehabilitation Sciences, University of Kentucky, Lexington, Kentucky 40536-0509
}

Summary: Two of the most prevalent secondary complications following spinal cord injury (SCI), besides loss of function and/ or sensation below the level of injury, are uncontrolled muscle spasticity and hypertensive autonomic dysreflexia. Despite the desires of the SCI community, there have been few advances in the treatment and/or management of these fundamental impediments to the quality of life associated with chronic SCI. Therefore, the purpose of this review is to focus on current drug treatment strategies that alleviate symptoms of spasticity and autonomic dysfunction. Subsequently, looking ahead, we discuss whether individuals suffering from autonomic dysreflexia and/or muscle spasms can take certain compounds that specifically and rapidly block the neurotransmission of pain into the injured spinal cord to get rapid relief for both aberrant reflexes for which painful stimuli below the level of SCI are common precipitants. Key Words: Spasms, hypertension, bradycardia, pharmacological, spinal cord injury, clinical interventions.

\section{SPINAL CORD INJURY: PREVALENCE AND PATHOPHYSIOLOGY}

The number of Americans in 2009 living with the typical devastating neurological deficits and debilitating somatic and autonomic reflexes that develop after chronic spinal cord injury ( $\mathrm{SCI}$ ) has been estimated to be approximately 262,000 persons (according to the University of Alabama website, www.nscisc.uab.edu). However, after decades of research and clinical trials, currently there is no effective pharmacological treatment for acute or chronic SCI, notably targeting recovery of lost sensory-motor function. Moreover, there have been few advances in the treatment and/or management of secondary complications associated with chronic SCI; in spite of the fact that both quadriplegics and paraplegics (when surveyed) considered alleviation of autonomic dysfunction (i.e., bowel, bladder, autonomic dysreflexia) higher in their priority when compared with walking, in respect to quality-of-life issues [1]. Therefore, this begs the question as to why basic and

Electronic supplementary material The online version of this article (doi:10.1007/s13311-011-0025-5) contains supplementary material, which is available to authorized users.

Address correspondence and reprint requests to: Alexander G. Rabchevsky Ph.D., Spinal Cord \& Brain Injury Research Center, University of Kentucky, B471, BBSRB 741 S. Limestone St., Lexington, KY 40536-0509. E-mail: agrab@uky.edu. clinical research efforts have not traditionally targeted such debilitating secondary complications that may have a greater potential for successful implementation, and more importantly may improve the quality of life in the chronic SCI population. The purpose of this review, consequently, is to describe current and emerging pharmacological interventions aimed at curtailing aberrant somatomotor and/or pseudomotor reflexes, manifested in uncontrolled muscle spasms or autonomic dysreflexia, respectively.

Spasticity is a common secondary impairment following both complete and incomplete SCI that is characterized by increased muscle tone (hypertonus), increased intermittent or sustained involuntary somatic reflexes (hyperreflexia), clonus, and painful muscle spasms in response to stretch and noxious cutaneous stimulation. In the animal model, it is has been demonstrated that spasticity results, in part, to increased glutamatergic signaling to the uninhibited motoneurons below the level of the injury [2]. Such aberrant somatic reflexes, if severe enough, can impact the ability of an individual with SCI to be able to perform routine activities of daily living, such as transfers, independent dressing, and management of bowel and bladder, with the grave potential of falling out of a wheelchair.

Alternatively, complete and less frequently incomplete $\mathrm{SCI}$ at or above high-thoracic (T5/6) levels, which comprise the majority of individuals with SCI, can also lead to a potentially life-threatening hypertensive con- 
dition termed autonomic dysreflexia, which is often triggered by painful somatic and/or visceral stimuli below the injury level [3]. This syndrome is characterized by a sustained elevated blood pressure, despite a decreased heart rate during the painful event, because the brainstem can no longer depress the intact sympathetic outflow below the level of SCI [4]. Episodes of autonomic dysreflexia often cause debilitating symptoms, including pounding headache, acute anxiety, shivering, blurred vision, flushing, and sweating [5]. In serious cases, paroxysmal hypertension can result in cerebral and spinal subarachnoid hemorrhage, seizures, and pulmonary edema [3].

One of the most common triggers of hypertensive autonomic dysreflexia is the distension of pelvic viscera (bladder and bowel) [6-8]. The consequent afferent barrage into the lumbosacral spinal cord results in massive sympathetic discharge below the level of the lesion, resulting in vasoconstriction of the muscular, splanchnic, and cutaneous vascular beds. The resultant paroxysmal hypertension produces a baroreceptor-mediated reflex bradycardia and vasodilatation above the lesion level, mediated by the vagus nerve [9]. Therefore, in addition to debilitating muscle spasms, many individuals with SCI suffer repeated unpleasant bouts of autonomic dysreflexia throughout the day and night, triggered by a full bladder or obstructed bowel/colorectum (constipation).

\section{CONVENTIONAL TREATMENTS FOR SPASTICITY}

The most commonly used medications that have demonstrated the most efficacious management of spasticity in clinical trials include baclofen, tizanidine and botulinum neurotoxin (BoNT) [10]. In addition, a second level of medications including benzodiazepine, dantrolene sodium, gabapentin, and pregabalin have demonstrated varying levels of effectiveness that support their potential use as anti-spastic medications. A recent systematic review of the literature suggests that although multiple types of drugs (i.e., oral, intrathecal, and/or injectable) have proven varying levels of efficacy in reducing spasticity, only the injectable treatments have been shown to have a positive effect on the negative consequences of upper motor neuron lesion (i.e., paresis, loss of fine motor control, loss of dexterity, fatigability) [11].

\section{Baclofen}

Currently, baclofen is the pharmacologic agent of choice for the treatment of SCI-induced spasticity. Baclofen is a derivative of the inhibitory neurotransmitter gamma-aminobutyric acid (GABA), which binds to $\mathrm{GABA}_{\mathrm{B}}$ receptors of the lamina I-IV of the spinal cord where primary sensory fibers terminate [12]. Binding of baclofen to the presynaptic terminal of the gabaergic interneuron leads to membrane hyperpolarization, which in turn leads to a restriction of the influx of calcium into the presynaptic terminal and endogenous transmitter release is reduced $[13,14]$. Baclofen is rapidly absorbed after oral administration and has a therapeutic half-life of about 3 to 4 hours. However, the use of this pharmacological agent can be limited by its adverse effects, which include sedation, fatigue, drowsiness, ataxia, and mental confusion [15-19], which can actually reduce the effectiveness of rehabilitation programs [11].

\section{Intrathecal baclofen}

In addition to the oral route of administration, baclofen has been shown to effectively manage spasticity when administered intrathecally [20-23]. Intrathecal administration is a long-term treatment with continuous, intraspinal administration via a catheter connected to an implantable pump. The rationale for this modality of baclofen administration has been to deliver the drug directly into the spinal fluid to allow higher concentrations in the spinal cord using lower dosages than the oral route, thereby optimizing the beneficial effects of baclofen while minimizing the well-established side effects. There is currently one registered clinical trial that is examining intrathecal baclofen for the management of spasticity (Table 1). However, this clinical trial is not recruiting subjects yet. Predominate indications for intrathecal baclofen are intractable and generalized spasticity of the legs, which may also involve the trunk musculature [24]. Importantly, although continuous intrathecal infusion of baclofen can be effective in the treatment of severe spasticity, there is concern for baclofen tolerance in many individuals that remains a critical issue [25]. Another report indicates that abrupt withdrawal from intrathecal baclofen can lead to the onset of a potentially life-threatening condition, referred to as intrathecal baclofen withdrawal syndrome. This syndrome can manifest as a form of autonomic dysreflexia or malignant hyperthermia [26].

\section{Tizanidine}

As with baclofen, tizanidine has been shown to effectively reduce spasticity originating from SCI, as well as multiple sclerosis. Tizanidine is an imidazole derivative and a centrally acting $\alpha 2$-adrenergic agonist that inhibits the release of excitatory amino acids in spinal interneurons, which increases presynaptic inhibition to motor neurons [27, 28]. In addition, tizanidine may act by facilitating the action of the inhibitory neurotransmitter glycine [29, 30]. Its peak anti-spasticity effects occur 1 to 2 hours following oral administration, with a therapeutic half-life of approximately 2.5 hours. Recently, it was demonstrated that in persons with SCI, 
tizanidine substantially reduces mechanical reflex responses without inducing comparable changes in intrinsic muscle properties [31]. The most common side effects of tizanidine are sedation, drowsiness, hypotension, dizziness, asthenia, muscle weakness, insomnia hallucination, and fatigue. These adverse effects are dose related and may be minimized by close titration in the clinical setting [11].

\section{Botulinum neurotoxin}

Botulinum neurotoxin (BoNT) is an injectible pharmacological agent that has been shown to effectively reduce spasticity arising from multiple etiologies (i.e., stroke, cerebral palsy, multiple sclerosis). Currently, there are seven immunologically distinct forms of BoNT; each of these forms are synthesized as a single-chain polypeptide of molecular mass approximately $150 \mathrm{kDa}$ [32]. BoNT can be differentiated into types A and B. Each of the type A BoNTs that are currently available (Botox, Allergan Irvine, CA; Dysport, Medicis Aesthetics Inc., Scottsdale, AZ; Xeomin, Merz Pharmaceuticals, Greensboro, NC) are produced from Clostridium botulinum bacteria and have similar pharmacological activity [11]. Specifically, BoNT inhibits vesicular acetylcholine release from the presynaptic nerve terminal at the neuromuscular junction, which essentially results in a chemical denervation [29, 32]. After binding the receptors to the synaptic vesicle protein SV2 on the presynaptic nerve terminals, BoNT is internalized via endocytosis [33]. To gain maximum biological activity, the $150 \mathrm{kDa}$ toxin polypeptide must be cleaved into a $100 \mathrm{kDa}$ heavy chain and a $50 \mathrm{kDa}$ light chain [32]. Following internalization, the light chain is translocated into the cytoplasm and inhibits the release of neurotransmitters by disrupting the functioning of the soluble N-ethylmaleimide-sensitive factor attachment protein receptor complex (SNARE) complex required for exocyctosis of synaptic vesicles [34]. The reduction in acetylcholine release effectively leads to a reduction in muscle contraction with a dose-dependent reduction in muscle strength. Recovery occurs through proximal axonal sprouting, which leads to muscle re-innervation and formation of a new neuromuscular junction. The clinical effects of BoNT injections can last for 3 to 4 months [35]. In addition to BoNTs well-established inhibition of acetylcholine release at the neuromuscular junction, pre-clinical studies have shown that it is able to inhibit neuropeptide release from primary afferent nociceptive $\mathrm{C}$ fibers and possibly from lightly myelinated A $\delta$ fibers [36].

Although baclofen, tizanidine, and BoNT are the most widely used anti-spastic pharmacological agents, there are several other drugs that have been tested clinically that have demonstrated varying levels of effectiveness in managing spasticity. These drugs include gabapentin, pregabalin, benzodiazepine, clonidine, dantrolene, and cannabis.

\section{Gabapentin}

Gabapentin (Pfizer, New York City, NY) is approved for the treatment of epilepsy and is widely used for the treatment of neuropathic pain [37-40]. Gabapentin is structurally similar to GABA, but it does not appear to bind to conventional $\mathrm{GABA}_{\mathrm{A}}, \mathrm{GABA}_{\mathrm{B}}$, glycine, or glutamate receptors [30]. Although gabapentin possesses multiple cellular mechanisms, recent work indicates the suggestion that inhibition of glutamatergic transmission may be pre-eminent in mediating its therapeutic effects in epilepsy, neuropathic pain, and perhaps spasticity [41]. Specifically, gabapentin has been shown to inhibit presynaptic glutamate release by modulating $\mathrm{Ca}^{2+}$ channels [42-47]. When incorporated as an adjunct to standard pharmacological interventions for spasticity, gabapentin demonstrates the potential to help decrease the manifestation of spasticity in individuals with SCI $[48,49]$. However, to date there has been no systematic examination of the efficacy of gabapentin as a single treatment for the management of SCI-induced spasticity. As with all drugs that interact directly with the central nervous system, gabapentin does have some potential side effects that can include somnolence, dizziness, and ataxia.

\section{Pregabalin}

Pregabalin (Lyrica [Pfizer]) is a relatively new drug that is considered to be the next generation of gabapentin. Similar to gabapentin, pregabalin was developed as a treatment for epileptic seizures, but it has evolved to include other indications, such as neuropathic pain [50, 51]. Their mechanisms of action require the binding to the high affinity $\alpha 2$-delta subunit protein of the voltagegated $\mathrm{Ca}^{2+}$ channels [52], thereby reducing release of excitatory neurotransmitters in the central nervous system [53]. To our knowledge, there has only been one retrospective case study that has examined the effects of pregabalin on spasticity [54]. This study concluded pregabalin may be effective in reducing the level of spasticity in a portion of persons with SCI. However, among the 22 participants in this study, 36\% reported significant side effects and discontinued use of this medication, whereas an additional $22 \%$ of the participants demonstrated no effect on their spasticity. There is currently only 1 registered clinical trial in which pregabalin is being examined, and spasticity is 1 of the secondary outcome measures (Table 1). However, this study is not currently recruiting subjects and further clinical studies are needed to establish the efficacy of this drug as an anti-spastic medication.

\section{Diazepam}

Diazepam belongs to the class of benzodiazepines and has been shown to cause muscle relaxation, which has led to their use in reducing the increased tone associated 
Table 1. "Spinal Cord Injury" and "Spasticity" and "Pharmacological" www.clinicaltrials.gov

\begin{tabular}{|c|c|c|c|}
\hline Treatment & Title of Trial & $\begin{array}{l}\text { Primary outcome } \\
\text { (study type) }\end{array}$ & $\begin{array}{c}\text { Clinical } \\
\text { phase status }\end{array}$ \\
\hline $\begin{array}{l}\text { Baclofen } \\
\text { (Programmable } \\
\text { implantable pump) }\end{array}$ & $\begin{array}{l}\text { Continuous intrathecal baclofen infusion } \\
\text { for the management of chronic spasticity } \\
\text { https://www.clinicaltrials.gov/ct } 2 / \text { show/ } \\
\text { NCT01051128?term=spinal+cord+injury+ } \\
\text { AND+spasticity\&recr=Open\&rank=10 }\end{array}$ & $\begin{array}{r}\text { Muscle spasticity } \\
\text { (interventional) }\end{array}$ & $\begin{array}{l}\text { Phase III not } \\
\text { yet recruiting }\end{array}$ \\
\hline $\begin{array}{l}\text { Cannabinoids } \\
\text { (nabilone) }\end{array}$ & $\begin{array}{l}\text { Effect of cannabinoids on spasticity in spinal cord } \\
\text { injured persons } \\
\text { https://www.clinicaltrials.gov/ct } 2 / \text { show/ } \\
\text { NCT01222468?term=spinal+cord+injury } \\
\text { +AND+spasticity\&recr=Open\&rank=2 }\end{array}$ & $\begin{array}{r}\text { Muscle spasticity } \\
\text { (interventional) }\end{array}$ & $\begin{array}{l}\text { Phase II not } \\
\text { yet recruiting }\end{array}$ \\
\hline $\begin{array}{l}\text { Pregabalin (Lyrica) - } \\
\text { Pfizer, New York } \\
\text { City, NY }\end{array}$ & $\begin{array}{l}\text { Study of pregabalin in the prevention of central } \\
\text { neuropathic pain in acute spinal cord injury } \\
\text { https://www.clinicaltrials.gov/ct } 2 / \text { show/ } \\
\text { NCT00879021?term=spinal+cord+injury+AND } \\
\text { +spasticity\&recr=Open\&rank=7 }\end{array}$ & $\begin{array}{l}\text { Neuropathic pain } \\
\text { and muscle spasticity } \\
\text { (interventional) }\end{array}$ & $\begin{array}{l}\text { Phase III not } \\
\text { yet recruiting }\end{array}$ \\
\hline
\end{tabular}

$\mathrm{SCI}=$ spinal cord injury.

with spasticity. The presumed action mechanism of the benzodiazepines is to enhance the binding efficacy of $\mathrm{GABA}_{\mathrm{A}}$ receptors. Binding of diazepam to the GABA receptor in the spinal cord increases chloride conductance resulting in the enhancement of presynaptic inhibition of sensory afferents involved with the aberrant somatosensory reflex arc [55]. The predominate side effect associated with diazepam that can limit its therapeutic efficacy as an anti-spasticity medication is sedation [29].

\section{Clonidine}

Clonidine is a centrally acting $\alpha 2$-adrenergic agonist that has been shown to decrease aspects of spasticity in patients with SCI [56, 57]. However, currently clonidine is rarely used as a single agent in the treatment of spasticity due, in part, to the adverse effects of this therapeutic agent, which can include bradycardia, hypotension, drowsiness, dizziness, and depression [30].

\section{Dantrolene}

Dantrolene sodium is a unique pharmacological agent in comparison with other anti-spastic medications because it exerts its effect directly at the level of skeletal muscles. Dantrolene sodium reduces contraction of skeletal muscle by a direct action on excitation-contraction coupling, by decreasing the amount of $\mathrm{Ca}^{2+}$ released from the sarcoplasmic reticulum. [58-61]. Unfortunately, this pharmacological agent tends to cause a generalized muscle weakness, which can directly affect the person's participation in physical rehabilitation, as well as overall functional improvement.

\section{Cannabinoids}

There has been anecdotal evidence that cannabis can reduce spasticity in persons with SCI, as well as a growing body of work that has examined this class of drug in managing spasticity in persons with multiple sclerosis. $\Delta 9$ tetrahydrocannabinoid (THC) is the main ingredient in cannabis. THC binds to both $\mathrm{CB}_{1}$ and $\mathrm{CB}_{2}$ receptors [62, 63]. Both cannabinoid receptor types are coupled through $\mathrm{G}$ proteins, negatively to adenylate cyclase and positively to mitogen-activated protein kinase. In addition, $\mathrm{CB}_{1}$ receptors are coupled to several ion channels. A recent review of randomized controlled trials evaluated the effect of cannabinoid therapy on the reduction of spasticity [64]. It was concluded that this pharmacological agent may reduce symptoms of spasticity in patients with multiple sclerosis, but that further studies are needed to show a significant effect on objective measurements of spasticity. It was recently demonstrated that a decrease in both the Ashworth scale and the spasticity sum score was observed in patients with SCI that were given THC [65]. Nevertheless, further randomized clinical trials are needed to elucidate the efficacy of this class of drugs as anti-spastic medications. Side effects of cannabinoids are reported to be generally mild and include dry mouth, dizziness, somnolence, nausea, and intoxication. In addition, there may be reason to be concerned about the use of therapeutic cannabinoids by adolescents, people predisposed to psychosis and pregnant women [66]. There is currently one registered clinical trial that is examining the effects of cannabinoids on spasticity (Table 1). However, this trial is not yet recruiting subjects.

\section{ETIOLOGY AND CONVENTIONAL TREATMENTS FOR AUTONOMIC DYSREFLEXIA}

Currently, prevention of autonomic dysreflexia remains the soundest approach. Importantly, one of the 
most common triggers of autonomic dysreflexia, as well as spasticity, is over-distension of the bladder and bowel. This means that these aberrant somatomotor and pseudomotor reflexive episodes occur repeatedly on a daily basis in individuals with a SCI above mid-thoracic levels, constituting the majority of SCI cases. Accordingly, draining the bladder alleviates the symptomatic hypertension in many cases of autonomic dysreflexia. In situations where noxious stimuli may be elusive, such as an ingrown toenail, and/or severe pressure sore, prophylactic treatment may be needed. To alleviate symptoms during such critical acute periods and avoid complications associated with uninhibited hypertension, anti-hypertensive medications with rapid onset and short duration should be used [9]. The development of animal models for autonomic dysreflexia, induced by noxious bladder and/or colorectal distension (CRD) [67, 68], has enabled the detailed analysis of temporal dynamics of induced hypertension $[69,70]$, injury-induced plasticity of primary afferents, propriospinal neurons and sympathetic preganglionic neurons [71-74], changes in the electrophysiology of sympathetic and sympatheticrelated interneurons [75], and effects of pharmacologic antagonists on pressor responses [68].

A subject of controversy is the mechanism(s) of sympathetic hyperactivity and increased mean arterial pressure (MAP). It has been suggested that cutaneous blood vessels show increased sensitivity to noradrenaline, based on the observation of prolonged vasoconstriction after sympathetic neural activity [76]. Other evidence suggests that abrupt loss of descending inhibition accompanied by changes in spinal neural activity are the cause of sympathetic hyper-reflexia following acute, complete SCI [70]. Notably, glutamatergic neurotransmission has been shown to contribute to spinal viscero-sympathetic initiation of episodic hypertension induced by CRD [77], and the development of autonomic dysreflexia is correlated with aberrant sprouting of nociceptive $\mathrm{C}$-fibers into the spinal cord below the injury level [78-80]. Therefore, painful distension of the pelvic viscera increases the excitation of expanded C-fiber terminals in the uninhibited lumbosacral spinal cord, which amplifies the activation of propriospinal neurons and effector sympathetic preganglionic neurons in the thoracolumbar cord $[4,71,78]$.

In reviewing the literature, despite the prevalence of this debilitating secondary syndrome, there are very few effective pharmacological agents that can be provided to an individual suffering from an acute or chronic bout of autonomic dysreflexia, notably outside the clinical setting. In fact, there are currently no ongoing, actively recruiting clinical trials for any compound designed to alleviate the symptoms of autonomic dysreflexia. A summary of clinical practice guidelines for managing autonomic dysreflexia can be obtained through the website for the Paralyzed Veterans of America (www. pva.org) [81]. The following is a partial list of compounds that have been used traditionally to treat the hypertensive symptoms accompanying autonomic dysreflexia.

\section{Nitrates and nifedipine}

In general, nitrates are the most commonly used therapeutics to lower blood pressure because they have a direct relaxant effect on vascular smooth muscles leading to dilation of coronary vessels and peripheral veins [82]. The topical application of 1 to 2 inches of $2 \%$ nitroglycerine (nitropaste) above the level of the lesion is effective, and it can be removed when the hypertensive crisis subsides [81]. Alternatively, nifedipine is a dihydropyridine L-type voltage-sensitive $\mathrm{Ca}^{2+}$ channel blocker that, when is administered in immediate release form (10 $\mathrm{mg}$ capsule), exerts coronary and peripheral vasodilator properties [83]. Although nifedipine significantly decreases resting MAP in spinal cord injured persons, and it prevents dangerous blood pressure elevations during cystometry-evoked dysreflexic hypertension [84], there is a lack of wellcontrolled clinical trials of nifedipine use for management of autonomic dysreflexia; therefore, evidence is primarily anecdotal and derived from selected cases. If such antihypertensive compounds do not alleviate symptoms, then intravenous administration of sodium nitroprusside is indicated for rapid titration of blood pressure. Notably, this and other secondary agents, such as well as clonidine, hydralazine, mecamylamine, and phenoxybenzamine, and also diazoxide, are primarily used in a monitored setting [3, $83,85]$, obviating their use on a routine daily basis.

\section{$\alpha$-Adrenergic blockers}

$\alpha$-Adrenergic receptor blocking agents (e.g., terazosin [a specific $\alpha 1$-adrenergic antagonist]) appear to prevent serious harm from autonomic dysreflexia, and it is efficacious in the first week of treatment in normotensive spinal cord injured patients with autonomic dysreflexia [86]. Taken once a day, terazosin completely abates dysreflexic symptoms and can be discontinued when the underlying problem has resolved, although persistent dizziness has been reported [87]. Another $\alpha 1$-adrenergic antagonist, prazosin ( $3 \mathrm{mg}$ twice a day, given for 2 weeks), is reported to reduce both the severity and duration of autonomic dysreflexia episodes in both cervical and high thoracic SCI individuals. It is well tolerated, but it does not significantly lower resting blood pressure, yet it does reduce the severity of headaches [88]. Although these findings infer that $\alpha 1$-adrenergic receptors play a key role in the pathogenesis of this syndrome, prazosin $(0.45 \mathrm{mg} / \mathrm{kg}$ i.v. $)$ and $\beta$-adrenergic antagonist, propranolol ( $4 \mathrm{mg} / \mathrm{kg}$ i.v.), have been administered individually or together to assess the contribution of $\alpha$-adrenergic and $\beta$-adrenergic mechanism, respectively. It was found that the pressor response to bladder 
distension was abolished completely only when combined $\alpha$-adrenergic and $\beta$-adrenergic blockades was administered. indicating that autonomic dysreflexia is mediated by both $\alpha$-adreneric and $\beta$-adrenergic receptors in the spinal rat [89]. On the contrary, however, increased MAP responses to CRD following intravenous infusion of the $\alpha 1$-adrenergic agonist, phenylephrine, showed no differences between intact and spinalized rats, thus questioning whether supersensitivity of $\alpha 1$-adrenergic agonists can completely account for the hypertensive bouts associated with autonomic dysreflexia [90].

In searching for other treatments to curtail the symptoms and prevent the catastrophic sequelae of autonomic dysreflexia, it is apparent that very little has been advanced in the past decade [91-93]. In fact, proper prophylaxis, including nonpharmacologic strategies, is still the preferred method to diminish the incidence and severity of cardiovascular dysfunction following SCI [94]. Surprisingly, there are no recent studies documenting whether pharmacological interventions are, in fact, superior to nonpharmacologic strategies. Because there are no ongoing clinical trials designed to examine novel treatments to ameliorate somatomotor spasticity, the question arises as to whether agents might exist that are also effective in treating pseudomotormediated autonomic dysreflexia. Notably, there is no single clinical intervention that is known to effectively attenuate the manifestation of both muscular spasticity and autonomic dysreflexia.

Because excitatory glutamatergic neurotransmission (i.e., painful) has been shown to contribute to spinal viscerasympathetic initiation of episodic hypertension [77], as well as to spasticity [95, 96], thwarting neurotransmission of noxious stimuli with pharmacological agents appears a tenable approach to reduce the severity of both of these aberrant reflexes. For example, as shown in Table 1, pregabalin is currently being assessed as an anti-spastic medication. Thus, there appears to be a common pathway by which painful stimuli are capable of inducing both spasticity and autonomic dysreflexia.

\section{SYNTHESIS OF FUTURE DIRECTIONS}

Gabapentin, and more recently pregabalin, are currently the drugs of choice for managing neuropathic pain in the SCI population, but neither are indicated for spasticity or autonomic dysreflexia. Inhibition of glutamatergic transmission may be pre-eminent in mediating its therapeutic effects in epilepsy, neuropathic pain, and perhaps spasticity [41]. Specifically, gabapentin has been shown to inhibit presynaptic glutamate release [42-46], and it effectively alleviates tail muscle spasticity in response to a painful stimulus in spinal rats [96]. As mentioned, when incorporated as an adjunct to standard pharmacological interventions, gabapentin is well-tolerated and demonstrates the potential to help decrease the manifestation of spasticity in individuals with SCI [48, 49].

As with spasticity, autonomic dysreflexia is thought to be mediated through abnormal glutamatergic neurotransmission. Therefore, a pharmacological agent that can manage pain and spasticity through the reduction of glutamate release may also have a beneficial effect on paroxysmal autonomic dysreflexia. Although numerous individuals with SCI are using gabapentin for the management of neuropathic pain, to date there has been no clinical evaluation of its potential efficacy in managing the incidence or severity of autonomic dysreflexia. On the contrary, however, it has recently been reported that gabapentin has striking efficacy in reducing both the severity of CRD-evoked dysreflexic hypertension and tail spasticity in response to stretch or painful pinch, in the same injured animals, weeks following complete SCI [97, 98].

From a clinical standpoint, it appears critical to assess gabapentin (or pregabalin) in relation to its onset time and duration of efficacy in comparison with other drugs routinely used for the management of spasticity and autonomic dysreflexia. Importantly, most current treatment options target specific symptomatic outcome measures (i.e., spasticity or hypertension) without taking into consideration that the painful stimuli has not been resolved, albeit unperceived by the individual with SCI. Alternatively, blocking pain neurotransmission into the central nervous system with gabapentin, and not opiate analgesics, which are addicting, has direct clinical relevance as a 3-pronged approach to alleviate dissimilar aberrant neurologic reflexes, supporting its novel indication for the effective management of spasticity and autonomic dysreflexia elicited, primarily, by noxious stimuli below the SCI level.

\section{CONCLUSIONS}

The purpose of this review was to focus on current drug treatment strategies that target spasticity and autonomic dysfunction in the chronic SCI population. Traditional anti-spastic medications include baclofen, tizanidine, BoNT, benzodiazepine, clonidine, dantrolene, and cannabis, whereas compounds to alleviate autonomic dysreflexia include anti-hypertensive nitrates, nifedipine, and adrenergic blockers. They are all reported to be useful, to some degree or another, but their effects are typically all-or-none. Although there is consensus among those living with SCI that these are serious secondary complications that affect quality of life [1], there are a few emerging clinical trials targeting either of the complications, notably as primary outcome measures. It is important to note that from a clinical perspective, moderate spasticity and autonomic dysreflexia are not dire, in and of themselves. In fact, low to moderate levels of each complication can be functional in a positive 
manner. For instance, moderate levels of spasticity provide tone to the trunk musculature that allows the person to perform transfers and use their upper extremities. Likewise, mild symptoms of autonomic dysreflexia provide an individual with valuable feedback that they may have a full bladder, constipation, and so forth. It is when each of these impairments is significantly heightened in concert that they become detrimental and impact a person's quality of life. Therefore, in looking ahead, it will be important to establish whether an individual suffering from autonomic dysreflexia and/or muscle spasms can take gabapentin to receive rapid relief, yet not completely abolish either of these sensory motor reflexes that serve to maintain muscle tone and act as a pathophysiological warning system.

Acknowledgments: This work was supported by endowments from the Spinal Cord and Brain Injury Research Center (AGR) and the McDougal Professorship in Physical Therapy (PHK). Full conflict of interest disclosure is available in the electronic supplementary material for this article.

\section{REFERENCES}

1. Anderson KD. Targeting recovery: priorities of the spinal cordinjured population. J Neurotrauma 2004;21:1371-1383.

2. Kitzman P. Changes in vesicular glutamate transporter 2, vesicular GABA transporter and vesicular acetylcholine transporter labeling of sacrocaudal motoneurons in the spastic rat. Exp Neurol 2006; 197:407-419.

3. Karlsson AK. Autonomic dysreflexia. Spinal Cord 1999;37:383-391.

4. Rabchevsky AG. Segmental organization of spinal reflexes mediating autonomic dysreflexia after spinal cord injury. Prog Brain Res 2006;152:265-274.

5. Kewalramani LS. Autonomic dysreflexia in traumatic myelopathy. Am J Phys Med 1980;59:1-21.

6. Harati Y. Autonomic disorders associated with spinal cord injury. In: Low PA, ed. Clinical autonomic disorders, 2nd edit. Philadelphia: Lippincott-Raven; 1997, 455-461.

7. Krassioukov AV, Furlan JC, Fehlings MG. Autonomic dysreflexia in acute spinal cord injury: an under-recognized clinical entity. J Neurotrauma 2003;20:707-716.

8. Snow JC, Sideropoulos HP, Kripke BJ, Freed MM, Shah NK, Schlesinger RM. Autonomic hyperreflexia during cystoscopy in patients with high spinal cord injuries. Paraplegia 1978;15:327-332.

9. Blackmer J. Rehabilitation medicine: 1. Autonomic dysreflexia. CMAJ 2003;169:931-935.

10. Pathak MS, Nguyen HT, Graham HK, Moore AP. Management of spasticity in adults: practical application of botulinum toxin. Eur $\mathrm{J}$ Neurol 2006;13(suppl 1):42-50.

11. Simon O, Yelnik AP. Managing spasticity with drugs. Eur J Phys Rehabil Med 2010;46:401-410.

12. Young RR. Baclofen. Arch Neurol 1977;34:722.

13. Young RR, Delwaide PJ. Drug therapy: spasticity (second of two parts). N Engl J Med 1981;304:96-99.

14. Yang K, Feng Y, Li Y. Baclofen inhibition of dorsal root-evoked inhibitory postsynaptic currents in substantia gelatinosa neurons of rat spinal cord slice. Brain Res 2001;900:320-323.

15. Abbruzzese G. The medical management of spasticity. Eur J Neurol 2002;(9 suppl 1):30-34; discussion 53-61.

16. Elovic E. Principles of pharmaceutical management of spastic hypertonia. Phys Med Rehabil Clin N Am 2001;12:793-816, vii.

17. Jamous A, Kennedy P, Psychol C, Grey N. Psychological and emotional effects of the use of oral baclofen: a preliminary study. Paraplegia 1994;32:349-353.
18. Kirshblum S. Treatment alternatives for spinal cord injury related spasticity. J Spinal Cord Med 1999;22:199-217.

19. Taricco M, Adone R, Pagliacci C, Telaro E. Pharmacological interventions for spasticity following spinal cord injury. Cochrane Database Syst Rev 2000; Issue 2. Art. No.: CD001131. doi:10.1002/ 14651858.CD001131.

20. Burns AS, Meythaler JM. Intrathecal baclofen in tetraplegia of spinal origin: efficacy for upper extremity hypertonia. Spinal Cord 2001;39:413-419.

21. Coffey JR, Cahill D, Steers W, et al. Intrathecal baclofen for intractable spasticity of spinal origin: results of a long-term multicenter study. J Neurosurg 1993;78:226-232.

22. Ivanhoe CB, Tilton AH, Francisco GE. Intrathecal baclofen therapy for spastic hypertonia. Phys Med Rehabil Clin N Am 2001;12:923938, viii-ix.

23. Zahavi A, Geertzen JH, Middel B, Staal M, Rietman JS. Long term effect (more than five years) of intrathecal baclofen on impairment, disability, and quality of life in patients with severe spasticity of spinal origin. J Neurol Neurosurg Psychiatry 2004; 75:1553-1557.

24. Yelnik AP, Simon O, Bensmail D, et al. Drug treatments for spasticity. Ann Phys Rehabil Med 2009;52:746-756.

25. Soni BM, Mani RM, Oo T, Vaidyanathan S. Treatment of spasticity in a spinal cord-injured patient with intrathecal morphine due to intrathecal baclofen tolerance-a case report and review of literature. Spinal Cord 2003;41:586-589.

26. Coffey RJ, Edgar TS, Francisco GE, et al. Abrupt withdrawal from intrathecal baclofen: recognition and management of a potentially life-threatening syndrome. Arch Phys Med Rehabil 2002;83: 735-741.

27. Palmeri A, Wiesendanger M. Concomitant depression of locus coeruleus neurons and of flexor reflexes by an alpha 2-adrenergic agonist in rats: a possible mechanism for an alpha 2-mediated muscle relaxation. Neuroscience 1990;34:177-187.

28. Wagstaff AJ, Bryson HM. Tizanidine. A review of its pharmacology, clinical efficacy and tolerability in the management of spasticity associated with cerebral and spinal disorders. Drugs 1997;53:435-452.

29. Burchiel KJ, Hsu FP. Pain and spasticity after spinal cord injury: mechanisms and treatment. Spine (Phila Pa 1976) 2001;26(24 suppl):S146-S160.

30. Kita M, Goodkin DE. Drugs used to treat spasticity. Drugs 2000;59:487-495.

31. Mirbagheri MM, Chen D, Rymer WZ. Quantification of the effects of an alpha-2 adrenergic agonist on reflex properties in spinal cord injury using a system identification technique. J Neuroeng Rehabil 2010;7:29.

32. Dolly JO, Aoki KR. The structure and mode of action of different botulinum toxins. Eur J Neurol 2006;13(suppl 4):1-9.

33. Dong M, Yeh F, Tepp WH, et al. SV2 is the protein receptor for botulinum neurotoxin A. Science 2006;312:592-596.

34. Dolly O. Synaptic transmission: inhibition of neurotransmitter release by botulinum toxins. Headache 2003;43(suppl 1):S16-24.

35. Pellizzari R, Rossetto O, Schiavo G, Montecucco C. Tetanus and botulinum neurotoxins: mechanism of action and therapeutic uses. Philos Trans R Soc Lond B Biol Sci 1999;354:259-268.

36. Aoki KR. Pharmacology and immunology of botulinum toxin serotypes. J Neurol. 2001;248(suppl 1):3-10.

37. Crawford P, Ghadiali E, Lane R, Blumhardt L, Chadwick D. Gabapentin as an antiepileptic drug in man. J Neurol Neurosurg Psychiatry 1987;50:682-686.

38. Levendoglu F, Ogun CO, Ozerbil O, Ogun TC, Ugurlu H. Gabapentin is a first line drug for the treatment of neuropathic pain in spinal cord injury. Spine (Phila Pa 1976). 2004;29:743-751.

39. Morello CM, Leckband SG, Stoner CP, Moorhouse DF, Sahagian GA. Randomized double-blind study comparing the efficacy of gabapentin with amitriptyline on diabetic peripheral neuropathy pain. Arch Intern Med 1999;159:1931-1937.

40. Rowbotham M, Harden N, Stacey B, Bernstein P, Magnus-Miller L. Gabapentin for the treatment of postherpetic neuralgia: a randomized controlled trial. JAMA 1998;280:1837-1842.

41. Wheeler G. Gabapentin. Pfizer. Curr Opin Investig Drugs 2002;3:470-477. 
42. Coderre TJ, Kumar N, Lefebvre CD, Yu JS. Evidence that gabapentin reduces neuropathic pain by inhibiting the spinal release of glutamate. J Neurochem 2005;94:1131-1139.

43. Coderre TJ, Kumar N, Lefebvre CD, Yu JS. A comparison of the glutamate release inhibition and anti-allodynic effects of gabapentin, lamotrigine, and riluzole in a model of neuropathic pain. $\mathrm{J}$ Neurochem 2007;100:1289-1299.

44. Maneuf YP, Blake R, Andrews NA, McKnight AT. Reduction by gabapentin of $\mathrm{K}+$-evoked release of [3H]-glutamate from the caudal trigeminal nucleus of the streptozotocin-treated rat. Br J Pharmacol 2004;141:574-579.

45. Maneuf YP, McKnight AT. Block by gabapentin of the facilitation of glutamate release from rat trigeminal nucleus following activation of protein kinase $\mathrm{C}$ or adenylyl cyclase. Br J Pharmacol 2001;134:237-240.

46. Shimoyama M, Shimoyama N, Hori Y. Gabapentin affects glutamatergic excitatory neurotransmission in the rat dorsal horn. Pain 2000;85:405-414.

47. Tran-Van-Minh A, Dolphin AC. The alpha2delta ligand gabapentin inhibits the Rab11-dependent recycling of the calcium channel subunit alpha2delta-2. J Neurosci. 2010;30:1285612867.

48. Gruenthal M, Mueller M, Olson WL, Priebe MM, Sherwood AM, Olson WH. Gabapentin for the treatment of spasticity in patients with spinal cord injury. Spinal Cord 1997;35:686-689.

49. Priebe MM, Sherwood AM, Graves DE, Mueller M, Olson WH. Effectiveness of gabapentin in controlling spasticity: a quantitative study. Spinal Cord 1997;35:171-175.

50. French JA, Kugler AR, Robbins JL, Knapp LE, Garofalo EA. Dose-response trial of pregabalin adjunctive therapy in patients with partial seizures. Neurology 2003;60:1631-1637.

51. Rosenstock J, Tuchman M, LaMoreaux L, Sharma U. Pregabalin for the treatment of painful diabetic peripheral neuropathy: a double-blind, placebo-controlled trial. Pain 2004;110:628638.

52. Fink K, Dooley DJ, Meder WP, et al. Inhibition of neuronal $\mathrm{Ca}(2+)$ influx by gabapentin and pregabalin in the human neocortex. Neuropharmacology. 2002;42:229-236.

53. Bryans JS, Wustrow DJ. 3-substituted GABA analogs with central nervous system activity: a review. Med Res Rev 1999;19:149-177.

54. Bradley LJ, Kirker SG. Pregabalin in the treatment of spasticity: a retrospective case series. Disabil Rehabil 2008;30:1230-1232.

55. Costa E, Guidotti A. Molecular mechanisms in the receptor action of benzodiazepines. Annu Rev Pharmacol Toxicol 1979;19:531545 .

56. Nance PW, Shears AH, Nance DM. Clonidine in spinal cord injury. Can Med Assoc J 1985;133:41-42.

57. Nance PW, Shears AH, Nance DM. Reflex changes induced by clonidine in spinal cord injured patients. Paraplegia 1989;27:296301.

58. Ellis KO, Carpenter JF. Mechanism of control of skeletal-muscle contraction by dantrolene sodium. Arch Phys Med Rehabil 1974;55:362-369.

59. Herman R, Mayer N, Mecomber SA. Clinical pharmacophysiology of dantrolene sodium. Am J Phys Med 1972;51: 296-311.

60. Weiser R, Terenty T, Hudgson P, Weightman D. Dantrolene sodium in the treatment of spasticity in chronic spinal cord disease. Practitioner 1978;221:123-127.

61. Stevenson VL. Rehabilitation in practice: spasticity management. Clin Rehabil 2010;24:293-304

62. Grotenhermen F. Pharmacokinetics and pharmacodynamics of cannabinoids. Clin Pharmacokinet 2003;42:327-360.

63. Pryce G, Baker D. Control of spasticity in a multiple sclerosis model is mediated by $\mathrm{CB} 1$, not $\mathrm{CB} 2$, cannabinoid receptors. Br J Pharmacol 2007;150:519-525.

64. Lakhan SE, Rowland M. Whole plant cannabis extracts in the treatment of spasticity in multiple sclerosis: a systematic review. BMC Neurol 2009;9:59.

65. Hagenbach U, Luz S, Ghafoor N, et al. The treatment of spasticity with Delta9-tetrahydrocannabinol in persons with spinal cord injury. Spinal Cord 2007;45:551-562.
66. Smith PF. New approaches in the management of spasticity in multiple sclerosis patients: role of cannabinoids. Ther Clin Risk Manag 2010;6:59-63.

67. Krassioukov AV, Weaver LC. Episodic hypertension due to autonomic dysreflexia in acute and chronic spinal cord-injured rats. Am J Physiol 1995;268(5 Pt 2):H2077-H2083.

68. Rivas DA, Chancellor MB, Huang B, Salzman SK. Autonomic dysreflexia in a rat model spinal cord injury and the effect of pharmacologic agents. Neurourol Urodyn 1995;14:141-152.

69. Maiorov DN, Fehlings MG, Krassioukov AV. Relationship between severity of spinal cord injury and abnormalities in neurogenic cardiovascular control in conscious rats. J Neurotrauma 1998:15:365-374.

70. Maiorov DN, Weaver LC, Krassioukov AV. Relationship between sympathetic activity and arterial pressure in conscious spinal rats. Am J Physiol 1997;272(2 Pt 2):H625-H631.

71. Hou S, Duale H, Cameron AA, Abshire SM, Lyttle TS, Rabchevsky AG. Plasticity of lumbosacral propriospinal neurons is associated with the development of autonomic dysreflexia after thoracic spinal cord transection. J Comp Neurol 2008;509:382-399.

72. Krassioukov AV, Weaver LC. Morphological changes in sympathetic preganglionic neurons after spinal cord injury in rats. Neuroscience 1996;70:211-225.

73. Krenz NR, Weaver LC. Sprouting of primary afferent fibers after spinal cord transection in the rat. Neuroscience 1998;85:443-458.

74. Krenz NR, Weaver LC. Changes in the morphology of sympathetic preganglionic neurons parallel the development of autonomic dysreflexia after spinal cord injury in rats. Neuroscience letters. 1998;243:61-64.

75. Chau D, Johns DG, Schramm LP. Ongoing and stimulus-evoked activity of sympathetically correlated neurons in the intermediate zone and dorsal horn of acutely spinalized rats. Journal of neurophysiology 2000;83:2699-2707.

76. Stjernberg L. Cutaneous vasomotor sensitivity to noradrenalin in spinal and intact man. Scand J Rehabil Med 1986;18:127-132.

77. Maiorov DN, Krenz NR, Krassioukov AV, Weaver LC. Role of spinal NMDA and AMPA receptors in episodic hypertension in conscious spinal rats. Am J Physiol 1997;273(3 Pt 2):H1266H1274.

78. Cameron AA, Smith GM, Randall DC, Brown DR, Rabchevsky AG. Genetic manipulation of intraspinal plasticity after spinal cord injury alters the severity of autonomic dysreflexia. J Neurosci 2006;26:2923-2932.

79. Krenz NR, Meakin SO, Krassioukov AV, Weaver LC. Neutralizing intraspinal nerve growth factor blocks autonomic dysreflexia caused by spinal cord injury. J Neurosci 1999;19:74057414.

80. Marsh DR, Wong ST, Meakin SO, MacDonald JI, Hamilton EF, Weaver LC. Neutralizing intraspinal nerve growth factor with a trkA-IgG fusion protein blocks the development of autonomic dysreflexia in a clip-compression model of spinal cord injury. $\mathrm{J}$ Neurotrauma 2002;19:1531-1541.

81. Medicine CfSC. Acute management of autonomic dysreflexia: individuals with spinal cord injury presenting to health-care facilities. J Spinal Cord Med 2002;25(suppl 1):S67-S88.

82. Torfgard KE, Ahlner J. Mechanisms of action of nitrates. Cardiovasc Drugs Ther 1994;8:701-717.

83. Lee BY, Karmakar MG, Herz BL, Sturgill RA. Autonomic dysreflexia revisited. J Spinal Cord Med 1995;18:75-87.

84. Thyberg M, Ertzgaard P, Gylling M, Granerus G. Effect of nifedipine on cystometry-induced elevation of blood pressure in patients with a reflex urinary bladder after a high level spinal cord injury. Paraplegia 1994;32:308-313.

85. Braddom RL, Rocco JF. Autonomic dysreflexia. A survey of current treatment. Am J Phys Med Rehabil 1991;70:234-241.

86. Chancellor MB, Erhard MJ, Hirsch IH, Stass WE, Jr. Prospective evaluation of terazosin for the treatment of autonomic dysreflexia. J Urol 1994;151:111-113.

87. Vaidyanathan S, Soni BM, Sett P, Watt JW, Oo T, Bingley J. Pathophysiology of autonomic dysreflexia: long-term treatment with terazosin in adult and paediatric spinal cord injury patients manifesting recurrent dysreflexic episodes. Spinal Cord 1998;36:761-770 
88. Krum H, Louis WJ, Brown DJ, Howes LG. A study of the alpha-1 adrenoceptor blocker prazosin in the prophylactic management of autonomic dysreflexia in high spinal cord injury patients. Clin Auton Res 1992;2:83-88.

89. Santajuliana D, Zukowska-Grojec Z, Osborn JW. Contribution of alpha- and beta- adrenoceptors and neuropeptide-Y to autonomic dysreflexia. Clin Auton Res 1995;5:91-97.

90. Landrum LM, Thompson GM, Blair RW. Does postsynaptic alpha 1-adrenergic receptor supersensitivity contribute to autonomic dysreflexia? Am J Physiol 1998;274(4 Pt 2): H1090-H1098.

91. Khastgir J, Drake MJ, Abrams P. Recognition and effective management of autonomic dysreflexia in spinal cord injuries. Expert Opin Pharmacother 2007;8:945-956.

92. McMahon D, Tutt M, Cook AM. Pharmacological management of hemodynamic complications following spinal cord injury. Orthopedics $2009 ; 32: 331$.
93. Naftchi NE, Richardson JS. Autonomic dysreflexia: pharmacological management of hypertensive crises in spinal cord injured patients. J Spinal Cord Med 1997;20:355-360.

94. Popa C, Popa F, Grigorean VT, et al. Vascular dysfunctions following spinal cord injury. J Med Life 2010;3:275-285.

95. Kitzman P. VGLUT1 and GLYT2 labeling of sacrocaudal motoneurons in the spinal cord injured spastic rat. Exp Neurol 2007;204:195-204.

96. Kitzman PH, Uhl TL, Dwyer MK. Gabapentin suppresses spasticity in the spinal cord-injured rat. Neuroscience 2007;149: 813-821.

97. Rabchevsky AG, Patel SP, Duale H, Lyttle TS, O’Dell CR, Kitzman PH. Gabapentin for spasticity \& autonomic dysreflexia after severe spinal cord injury. Spinal Cord 2011;49:99-105.

98. Rabchevsky AG, Patel SP, Lyttle TS, O’Dell CR, Kitzman PH. Effects of chronic versus acute gabapentin administration on spasticity \& autonomic dysreflexia after severe spinal cord injury. J Neurotrauma 2010;26:A-73. Abstract. 